This is the author's final, peer-reviewed manuscript as accepted for publication. The publisher-formatted version may be available through the publisher's web site or your institution's library.

\title{
Cytostatic Inhibition of Cancer Cell Growth by Lignan Secoisolariciresinol Diglucoside
}

\author{
Allan Ayella, Soyoung Lim, Yu Jiang, Dingbo Lin, Weiqun Wang, ${ }^{*}$ \\ Department of Human Nutrition, Kansas State University, Manhattan, KS 66506 \\ Takeo Iwamoto, John Tomich, \\ Department of Biochemistry, Kansas State University, Manhattan, KS 66506 \\ *Corresponding author. Tel.: +1 785532 0153; fax: +1 7855323132. \\ E-mail address: wwang@ksu.edu (W. Wang)
}

\section{How to cite this manuscript (APA format)}

If you make reference to this version of the manuscript, use the following citation format:

Ayella, A., Lim, S., Jiang, Y., Iwamoto, T., Lin, D., Tomich, J., \& Wang, W. (2010) Cytostatic Inhibition of Cancer Cell Growth by Lignan Secoisolariciresinol Diglucoside. Retrieved from http://krex.ksu.edu

\section{Published Version Information}

Citation: Ayella, A., Lim, S., Jiang, Y., Iwamoto, T., Lin, D., Tomich, J., \& Wang, W. (2010) Cytostatic Inhibition of Cancer Cell Growth by Lignan Secoisolariciresinol

Diglucoside. Nutrition Research. Volume: 30, Issue: 11, Pages: 762-769

Copyright: Copyright (C) 2010 Elsevier B.V.

Digital Object Identifier (DOI): doi:10.1016/j.nutres.2010.10.002

Publisher's Link:

http://www.elsevier.com/wps/find/journaldescription.cws_home/525483/

This item was retrieved from the K-State Research Exchange (K-REx), the institutional repository of Kansas State University. K-REx is available at http://krex.ksu.edu 


\section{Cytostatic Inhibition of Cancer Cell Growth by Lignan Secoisolariciresinol Diglucoside}

3 Allan Ayella ${ }^{a}$, Soyoung Lim ${ }^{\text {a }}$, Yu Jiang ${ }^{a}$, Takeo Iwamoto ${ }^{b}$, Dingbo Lin ${ }^{a}$, John Tomich $^{\text {, }}$,

4 Weiqun Wang ${ }^{a, *}$

5 a Department of Human Nutrition, ${ }^{b}$ Department of Biochemistry, Kansas State University,

6 Manhattan, KS 66506

7

8 * Corresponding author. Tel.: +1 785532 0153; fax: +1 785532 3132. E-mail address:

9 wwang@ksu.edu (W. Wang).

10 
11 Abbreviations:

12 SDG, secoisolariciresinol diglucoside;

13 HPLC-MS/ESI, high performance liquid chromatography-mass spectrometry /electron spray

14 ionization. 
Our previous study demonstrated that lignan metabolites enterolactone and enterodiol

17 inhibited colonic cancer cell growth by inducing cell cycle arrest and apoptosis. However, the

18 dietary lignans are naturally present as glycoside precursors such as secoisolariciresinol

19 diglucoside (SDG) that has not been evaluated yet. This study is thus to test a hypothesis that the

20 dietary SDG might have a different impact from its metabolites in human colonic SW480 cancer

21 cells. Treatment with SDG at 0-40 $\mu \mathrm{M}$ up to $48 \mathrm{hrs}$ resulted in a dose- and time-dependent

22 decrease in cell numbers, which was comparable to enterolactone. The cell growth inhibited by

23 SDG appeared not to be mediated by cytotoxicity, but cytostatic mechanism with an increase of

24 cyclin A expression. Furthermore, HPLC analysis indicated SDG in the media was much more

25 stable than enterolactone (95\% of SDG survival vs. $57 \%$ of enterolactone after 48 -hr treatment).

26 When the cells were treated with either enterolactone or SDG at $40 \mu \mathrm{M}$ for $48 \mathrm{hrs}$, the

27 intracellular levels of enterolactone as measured by HPLC-MS/ESI were about $8.3 \times 10^{-8}$

$28 \mathrm{nmol} / \mathrm{cell}$, but intracellular SDG or potential metabolites were undetectable. Taken together,

29 SDG demonstrated similar effects on cell growth, cytotoxicity, and cell cycle arrest when

30 compared with its metabolite enterolactone. However, the reliable stability and undetectable

31 intracellular SDG in treated cells may suggest that a metabolism of SDG, if exposed directly to

32 the colonic cells, could be different from the known degradation by microorganisms in human 33 gut.

34 Keywords: Lignans, secoisolariciresinol diglucoside, enterolactone, cancer prevention, SW480 35 cells 


\section{Introduction}

Potential cancer prevention by dietary lignan glycoside, i.e., secoisolariciresinol

diglucoside (SDG), has been suggested to be mediated through its metabolites, enterolactone and

39 enterodiol [1-5]. The chemical structures of SDG and its mammalian metabolite enterolactone

40 are shown in Figure 1. Enterolactone and enterodiol are anaerobically formed via colonic

41 bacterial fermentation [6-7]. Besides the bacterial fermentation, enterolactone and enterodiol can

42 also be formed by other cell organelles such as a study that showed liver microsomes could

43 generate lignan aglycones [8].

44 Many studies show that SDG has cancer preventive properties in animal models. Our

45 previous study demonstrated that SDG levels in wheat bran from various wheat cultivars were

46 correlated to antitumor activities in APC-Min mice [9]. We also found that dietary SDG at

$47 \quad 0.01 \%$ significantly reduced azoxymethane-induced formation of aberrant crypt foci in F344 rats

48 [10]. In addition, we have shown that enterolactone and enterodiol or both in combinations

49 inhibit human cancer cell growth through inducing S-phase cell cycle arrest and apoptosis [9].

50 Experimental animal studies by others show that dietary supplementation with $73-293 \mu \mathrm{mol} / \mathrm{kg}$

51 SDG inhibits experimental metastasis of B16BL6 murine melanoma cells in C57BL/6 mice [11].

52 However, no in vitro studies have been done to specify cancer preventive property of SDG,

53 although SDG metabolites, enterolactone and enterodiol, have been intensively investigated [12-

54 18]. Therefore, we hypothesized that the dietary SDG might have a different impact from its

55 metabolites in human colonic SW480 cancer cells.

56 The objective in this study is to determine the cancer preventive effects of SDG in human

57 colon cancer SW480 cells. The effects of SDG on cellular growth and the underlying

58 mechanisms regarding cytotoxicity and cell cycle interruption were studied and compared with 
59 its metabolite enterolactone. SDG was also investigated for stability in the media when compared

60 to enterolactone. Furthermore, HPLC- MS/ESI was used to evaluate whether SDG were taken up

61 intracellularly into the cells, which may provide insight into its bioavailability and cancer

62 preventive impact.

\section{2. Methods and materials}

\section{2.1. Cell culture and treatments}

The human colon cancer SW480 cells were purchased from the American Type Culture

66 Collection (Rockville, MD), and cultured in the Dulbecco's Modified Eagle Media supplemented

67 with $10 \%$ fetal bovine serum and 1\% penicillin/streptomycin (Sigma-Aldrich, St. Louis MO).

68 The cells were cultured in either 6-well plates or $200 \mathrm{~mL}$ volumetric flasks at $37{ }^{\circ} \mathrm{C}$ in $5 \% \mathrm{CO}_{2}$

69 until $60-80 \%$ confluence. At this confluence, cells were treated with either SDG or enterolactone

70 at $0-40 \mu \mathrm{M}$ up to $48 \mathrm{hrs}$, at which the cells had reached less than $100 \%$ confluence. SDG was

71 purchased from ChromaDex (Irvine, CA), while enterolactone was purchased from either Sigma-

72 Aldrich (St Louis, Mo) or ChromaDex. SDG or enterolactone was dissolved in DMSO and then

73 mixed with fresh media to achieve the final concentrations. DMSO was kept less than $0.2 \%$ in

74 the final treatment, which did not alter cell growth or cell cycle measurements when compared

75 with DMSO-free media (data not shown). After treatment, the cells were detached and counted

76 by hemacytometer as described by our previous publication [9].

77 2.2. Cytotoxicity assay

78 The cell viability was measured in the adherent cells by trypan blue staining [9]. The

79 viable cell numbers in the treated cells were compared with that in the vehicle controls.

$80 \quad$ 2.3. Cell cycle analysis 
The cell cycle analysis was done as previously described [9-10]. Briefly, the cells were

82 fixed in ethanol, centrifuged and then the pellet was resuspended in the phosphate buffer saline

83 solution at $\mathrm{pH} 7.4$, containing $20 \mathrm{~g} / \mathrm{L}$ propidium iodide and $5000 \mathrm{U} / \mathrm{L}$ of RNase (Promega) at 37

$84{ }^{\circ} \mathrm{C}$ for $30 \mathrm{~min}$. DNA flow cytometric analysis (FACSCaliber, Becton Dickinson, Newyork, NJ)

85 was performed with an excitation at $488 \mathrm{~nm}$ and an emission at $630 \mathrm{~nm}$.

86 2.4. Western blot analysis for cyclin A protein

87 As described in our previous publication [9], the treated cells were harvested and

88 suspended in Triton lysis buffer. Protein concentration was measured by the Pierce BCA protein

89 assay kit (Thermo Fisher Scientific, Rockford, IL), and $30 \mu \mathrm{g}$ of whole cell protein was

90 electrophoresed on $12 \%$ SDS polyacrylamide gels and transferred to pure nitrocellulose

91 membrane using semi-dry transfer cell (Trans-blot SD cell, BIO-RAD, Hercules, CA). The

92 membrane was blocked in TDN buffer at $4{ }^{\circ} \mathrm{C}$ for $1 \mathrm{hr}$. Then the membrane was incubated

93 overnight with 1:1,000 dilution of anti-cyclin A and anti- $\beta$-actin (Cell Signaling Technology

94 Inc., Danvers, MA). After washing, the membrane was incubated in anti-IgG of horse-radish

95 peroxidase-conjugated secondary antibody (1:10,000) (Santa Cruz Biotechnology, Santa Cruz,

$96 \mathrm{CA}$ ) for $1 \mathrm{hr}$. The specific protein band was visualized by applying the Super signal west femto

97 maximum sensitivity substrate (Thermo Fisher Scientific, Rockford, IL). The band was scanned

98 and detected by using FlouroChemTM 8800 Advanced Imagine System (Alpha Innotech, San

99 Leandro, CA). The cyclin A protein levels at 55-kDa were normalized as ratios of the density of

$100 \quad \beta$-actin at 43-kDa in the same sample and then presented as the percentages of the vehicle

101 controls.

102 2.5. HPLC quantification of SDG and enterolactone 
HPLC-UV quantification of SDG and enterolactone was done according to previous

104 methods $[1,9]$ with slight modification. Generally, the cell culture medium was separated by

105 centrifugation at $1000 \mathrm{X}$ g for $10 \mathrm{~min}$ from the treated cells after treatment with $0-40 \mu \mathrm{M}$ SDG

106 or enterolactone for 48 hrs. SDG and enterolactone were analyzed by HPLC using a C18

107 column $(5 \mu \mathrm{m}, 250$ X 4.6 i.d. mm, Alltech, Deerfield, Il), eluted with a 5\% acetonitrile in 0.01

$108 \mathrm{mM}$ phosphate buffer, $\mathrm{pH} 2.8$ (solvent A) over 100\% acetonitrile (solvent $\mathrm{B}$ ) at a flow rate of 1

$109 \mathrm{~mL} / \mathrm{min}$. A gradient runs at $0 \%$ solvent B for $10 \mathrm{~min}, 0-100 \%$ solvent B for $20 \mathrm{~min}$, and 100\%

110 solvent B for $10 \mathrm{~min}$. Peaks were detected by UV-monitoring at $283 \mathrm{~nm}$. The enterolactone and

111 SDG peak was identified according to both retention time and spectrum by comparison with a

112 commercial standard, respectively. A linear HPLC calibration curve for both lignans was

113 obtained for the concentrations between 0 and100 $\mu \mathrm{M}$.

114 2.6. HPLC-MS/ESI analysis of intracellular levels of SDG and enterolactone

115 The SW480 cells treated with $40 \mu \mathrm{M}$ SDG or enterolactone for $48 \mathrm{hr}$ were harvested by

116 detaching with trypsin-EDTA as previously described [9] and centrifuged at $1000 \mathrm{Xg}$ for 10

$117 \min$. The supernatant was discarded and the pellet was washed by three times and resuspended in

$1180.01 \mathrm{M}$ phosphate buffered saline at $\mathrm{pH}$ 7.4. The resulting solution was homogenized under an

119 ice bucket followed by three 1:1 diethyl ether extractions. The upper organic layer containing the

120 lignans was evaporated to dryness in a water bath set at $35^{\circ} \mathrm{C}$ under vacuum condition. The

121 residue remaining at the bottom of the flask was re-dissolved in $100 \%$ methanol and ultra-

122 centrifuged at 40,000 X g for 30 minutes. HPLC-MS/ESI analysis was performed with an

123 Esquire 3000 plus mass spectrometer (Bruker Daltonics, GmbH, Billerica, MA) coupled to an

124 Agilent (Agilent, Waldbronn, Germany) 1100 series HPLC system. Separations were achieved

125 with a Synergi Max-RP (Phenomenex, Torrance, CA) column (20 x 2 mm i.d., $2 \mu \mathrm{m})$ with a 
126 linear 2.5 min. gradient from $30-95 \%$ acetonitrile in water containing $0.1 \%$ formic acid. The

127 MS/ESI spectra were acquired in positive ionization mode from $\mathrm{m} / \mathrm{z} 100$ to 1000 . The mass

128 spectrometry instrument was controlled by the esquire control 5.3 software (Bruker Daltonics,

$129 \mathrm{GmbH}$, Billerica, MA). The data were processed with Data analysis 3.3 software (Bruker

130 Daltonics, GmbH, Billerica, MA).

$131 \quad$ 2.7. Statistical analyses

132 All data was analyzed by the SAS statistical system, version 8.2. The cell number, cell

133 cycle and HPLC data were analyzed by 2-way ANOVA using a general linear model procedure

134 followed by Fisher's protected least square difference. The relationship between lignan

135 concentrations remaining in cell culture media and the original lignan amounts was determined

136 by linear regression by using the Pearson's correlation coefficients (r). The results are present as

137 means \pm SEM and a probability at $<0.05$ is considered significantly.

\section{3. Results}

139 3.1. Cell growth inhibition

140 As shown in Figure 2, treatment of SW480 cells with either SDG or enterolactone at 0-40

$141 \mu \mathrm{M}$ up to $48 \mathrm{hrs}$ resulted in a dose- and time-dependent decrease in cell number when compared

142 with the vehicle control.

143 3.2. Cytotoxicity Assay

144 The cell viability was generally greater than $80 \%$ in the adherent cells, and the treated

145 cells did not differ significantly from the vehicle-treated controls (data not shown).

146 3.3. Cell cycle Analysis

147 The treatment of SW480 cells with either SDG or enterolactone at 30-40 $\mu \mathrm{M}$ for either 24

148 or 48 hrs induced cell cycle arrest at S-phase significantly (Figure 3). As the percentage of cells 
149 in S-phase increased, the percentage of cells at both G1 and G2/M phases decreased

150 correspondingly.

151 3.4. Cyclin A protein levels

152 The levels of cyclin A protein significantly increased in the cells treated with SDG at 20-

$15340 \mu \mathrm{M}$ or enterolactone at $40 \mu \mathrm{M}$ for $48 \mathrm{hrs}$ when compared to the vehicle control (Figure 4).

154 3.5. Stability of SDG vs. enterolactone in the medium

155 The concentrations of SDG and enterolactone in the cell culture media after treatment

156 were measured over the time by HPLC method. Figure 5A showed a representative HPLC

157 chromatograph of the standard SDG with two common SDG metabolites, i.e., enterodiol and

158 enterolactone. The retention times of SDG, enterodiol, and enterolactone are 20.5, 25.4, and 28.6

159 min, respectively. By using this established HPLC method, either enterolactone or SDG was

160 detectable in the media after treatment as shown in Figure 5B and 5C, respectively.

161 The stability of SDG and enterolactone in the media with or without SW480 cells for 48

162 hr was further evaluated. As shown in Figure 6, SDG generally exhibited greater stability than

163 enterolactone in the media with or without the cells. About $95 \%$ of SDG at $40 \mu \mathrm{M}$ in the media

164 without the cells was detectable after $48 \mathrm{hr}$ treatment verse $57 \%$ of enterolactone only. Both

165 SDG and enterolactone at $10-40 \mu \mathrm{M}$ resulted in the greater losses in the presence of SW480

166 cells, likely due to uptake and/or degradation by cellular enzymes.

167 3.6. Intracellular levels of SDG verse enterolactone

168 In comparison with the representative HPLC chromatograph of SDG, enterodiol,

169 enterolactone, and internal standard flavone (Figure 7A), a HPLC chromatograph in Figure 7B

170 demonstrated a detectable enterolactone from the intracellular extracts of total 210 million cells 
171 after treatment with enterolactone at $40 \mu \mathrm{M}$ for $48 \mathrm{hr}$. However, SDG was not detectable from

172 the intracellular extracts of the treated cells under a similar condition as shown in Figure 7C.

173 HPLC detection for both SDG and enterolactone peaks was further identified by MS/ESI

174 analysis. The representative MS spectra were shown in Figure 8. SDG has a molecular mass at

175687 and thus was shown in $\mathrm{m} / \mathrm{z}$ of 687.02 . Furthermore, the ion peak at $\mathrm{m} / \mathrm{z}$ of 704.09 could be

176 interpreted as a combination of SDG with a molecule of water [SDG $\left.+\mathrm{H}_{2} \mathrm{O}\right]^{+}$, and the ion peak at

$177 \mathrm{~m} / \mathrm{z}$ of 709.08 is most likely the sodium salt of SDG $[\mathrm{SDG}+\mathrm{Na}]^{+}$. The major ion identified as

178 enterolactone had a mass/charge ratio of $\mathrm{m} / \mathrm{z}$ at 298.46 (Figure $8 \mathrm{~B}$ ).

\section{Discussion}

Lignans are a group of the phytochemicals that compose of phenylpropane dimer linked

181 by $\beta-\beta$ bonds with a 1,4-diarylbutane structure, which are present abundantly in flaxseed, but

182 also present in various grains such as wheat [9-10]. The most prominent lignan in dietary grains

183 is SDG. When ingested, SDG undergoes bacterial fermentation to generate lignan mammalian

184 metabolites, i.e., enterodiol and enterolactone [10]. Although both enterodiol and enterolactone

185 have been shown for cancer preventive activities, little information is available about the

186 potential cancer preventive property of SDG by itself. The absorption of mammalian lignans is

187 usually poor, resulting in a low range of $\mathrm{nM}$ up to a few $\mu \mathrm{M}$ in the human plasma and/or urine

188 samples [19]. However, lignan precursors-enriched foods may reach to the gut and provide a

189 much high dose into the colonic contents. Bach Knudsen et al. once reported that the mammalian

190 lignans could be detected up to $175 \mu \mathrm{mol} / \mathrm{kg}$ fecal samples in the stool of pigs fed rye based diets

191 containing total lignans at $137 \mu \mathrm{mol} / \mathrm{d}$ [20], indicating that a much high dose of dietary lignans

192 could be physiologically achieved in the colonic contents. Although the physiological

193 significance of such high doses of lignans presented in the colonic contents is not defined, we

Page 10 of 23 
194 hypothesized that dietary SDG, in addition to be a precursor of enterodiol and enterolactone,

195 might influence the colonic mucosal cells in situ. Furthermore, a rational plan for using the

196 concentrations up to $40 \mu \mathrm{M}$ tested in this study was also supported.

197 In this study, we demonstrate that SDG inhibits colon cancer cell growth by inducing S-

198 phase cell cycle arrest, a characteristic previously attributable mostly to its metabolites. In

199 addition, not only does SDG inhibit colon cancer growth but it is also much more stable than

200 enterolactone in the cell culture media.

201 When we reject our hypothesis that SDG might provide different effect on cancer cell

202 growth when compared with its metabolite entrolantone, we found the effects of SDG and

203 enterolactone on the cell growth, cell viability, and cell cycle arrest are comparable. However, a

204 higher stability of SDG in the media than enterolactone may be related to the nature of chemical

205 structure and the chemical groups attached. The bulky glucose moieties in the SDG structure

206 may prevent attack from the possible electrophiles in the cell culture media. In addition, the

207 presence of two methoxy groups attached to outer carbon benzene rings in the SDG structure

208 may allow for an increased electron delocalization, and hence could be more stable in the

209 inherent SDG structure [21]. This notion is consistent with the observation that SDG was stable

210 in the bread products during baking [22]. On the other hand, the reactive lactone group on

211 enterolactone tends to be unstable as reported in antibacterial studies by using lactone functional

212 groups [23, 24]. In addition, the accessibility of enterolactone functional groups to the potential

213 electrophiles appears high. Although, ChemDraw ultra software predicts a negative overall

214 enthalpy on the enterolactone structure [25], the lactone functional group and the openness of the

215 enterolactone structure may tend to overshadow this effect towards increased enterolactone

216 instability. 
It is a challenge to detect intracellular levels of a phytochemical such as lignans. Based

218 upon our previous experience in flavonoid apigenin [26] and lignan analysis [9-10, 27], HPLC

219 method is usually sensitive at nanograms per million cells. By collecting over 210 million cells

220 from a total of 21 cell culture flasks, the intracellular levels of enterolactone in enterolactone-

221 treated cells were indeed measurable. HPLC-MS/ESI further confirmed enterolactone as a

222 molecular ion with $\mathrm{m} / \mathrm{z}$ at 298.47. However, the intracellular levels of SDG were not detectable,

223 nor the common metabolites enterodiol and enterolactone, in SDG-treated cells. Some novel

224 metabolites were revealed by MS/ESI, but we limited to identify the chemical structures for

225 those potential metabolites in this moment. Although SDG and/or its metabolites were not

226 detectable in the treated cells, it should be noted that it was not expected for intact SDG to be

227 absorbed, since a phytochemical glycoside is usually deglycosilation by $\beta$-glucosidase or lactase

228 phlorozin hydrolase [28]. Therefore, SDG-treated cells with undetectable intracellular SDG or its

229 currently known metabolites observed in this study may provide novel insight into SDG

230 metabolism and bioavailability if exposed directly to the colonic cells before degradation by

231 microorganisms in human gut.

232 In conclusion, SDG displayed significant anticancer effects as indicated by the inhibition

233 of colon cancer cell growth. This effect was associated partly with the induction of cell cycle

234 arrest at S-phase. Also, the stability of SDG is much higher in the cell culture media than

235 enterolactone. Intracellular level studies revealed that enterolactone taken up by enterolactone-

236 treated cells, but not SDG as it was undetectable in SDG-treated cells. The reliable stability and

237 undetectable intracellular SDG in treated cells may suggest a metabolism of SDG, if exposed

238 directly to the colonic cells, could be different from the currently known degradation by

239 microorganisms in human gut. 


\section{Acknowledgments}

242 This work was supported in part by USDA Cooperative Project KS 680-0199184 and KS

243 410-0214022, Agricultural Experiment Station, Kansas State University (contribution journal

244 No. 04-355-J).

Page 13 of 23 


\section{References}

[1] Richard SE, Orcheson LJ, Seidl MM, Luyengi L, Fong HH, Thompson LU. Dosedependent production of mammalian lignans in rats and in vitro from the purified precursor secoisolariciresinol diglucoside in flax seed. J Nutr 1996;126:2012-9.

[2] Wang LQ, Meselhy MR, Li Y, Qin GW, Hattori M. Human intestinal bacteria capable of transforming secoisolariciresinol diglucoside to mammalian lignans, enterodiol and enterolactone. Chem Pharm Bull 2000;48:1606-10.

[3] Heinonen S, Nutmi T, Liukkonen K, Poutanen K, Wahaha K, Deyama T, Nishibe S, Aldlercruetz H. In vitro metabolism of plant lignans: New precursors of mammalian lignans enterolactone and enterodiol. J Agric Food Chem 2001;49:3178-86.

[4] Bannawart C, Adlercreutz H, Wahala K, Brunow G, Hase T. Detection and identification of the plant lignans lariciresinol, isolariciresinol and secoisolariciresinol in human urine. Clin Chim Acta 1989;180:293-301.

[5] Rickard ES, Thompson UL. Urinary composition and postprandial blood changes in 3HSecoisolariciresinol diglycoside (SDG) metabolites in rats do not differ between acute and chronic SDG treatments. J Nutr 2000;130:2299-305.

[6] Nesbitt PD, Lam Y, Thompson UL. Human metabolism of mammalian lignan precursors in raw and processed flaxseed. Am J Clin Nutr 1998;69:549-55.

[7] Clavel T, Henderson G, Engst W, Dore J, Blaut M. Phylogeny of human intestinal bacteria that activate the dietary lignan secoisolariciresinol diglucoside. FEMS Microbiol Ecol $2006 ; 55: 471-8$.

[8] Niemeyer HB, Honig MD, Kulling ES, Metzler M. Studies on the metabolism of plant lignans secoisolariciresinol and matairesinol. J Agric Food Chem 2003;51:6317-25. 
[9] Qu H, Madl R, Takemoto D, Baybutt R, Wang W. Lignans are involved in the antitumor activity of wheat bran in colon cancer SW480 cells. J Nutr 2005;135:598-602.

[10] Wang W, Ayella A, Jiang Y, Ouyang P, Qu H. Wheat lignans: promising cancer preventive agents. In: Liu L, editor. Wheat Antioxidants. Hoboken, New Jersey: John Wiley \& Sons, Ltd.; 2008. P. 264-72.

[11] Chen J, Tan KP, Ward WE, Thompson LU. Exposure to flaxseed or its purified lignan during suckling inhibits chemically induced rat mammary tumorigenesis. Exp Biol Med 2003;228:951-8.

[12] Le Bail JC, Champavier Y, Chulia AJ, Habrioux G. Effects of phytoestrogens on aromatase, 3 beta and 17 beta-hydroxysteroid dehydrogenase activities and human breast cancer cells. Life Sci 2000;66:1281-91.

[13] Whitehead SA, Lacey M. Phytoestrogens inhibit aromatase but not 17beta-hydroxysteroid dehydrogenase (HSD) type 1 in human granulosa-luteal cells: evidence for FSH induction of 17beta-HSD. Human Reprod 2003;18:487-94.

[14] Brooks JD, Thompson LU. Mammalian lignans and genistein decrease the activities of aromatase and 17beta-hydroxysteroid dehydrogenase in MCF-7 cells. J Steroid Biochem Mol Biol 2005;94:461-7.

[15] Wang C, Kurzer MS. Effects of phytoestrogens on DNA synthesis in MCF-7 cells in the presence of estradiol or growth factors. Nutr Cancer 1998;31:90-100.

[16] Webb LA, McCullough LM. Dietary lignans: potential role in cancer prevention. Nutr Cancer 2005;51:118-31.

[17] Sung MK, Lautens M, Thompson LU. Mammalian lignans inhibit the growth of estrogenindependent human colon tumor cells. Anticancer Res 1998;18:1405-8. 
[18] Danbarra N, Yuri T, Tsujita-Kyutoku M, Uehara N, Tsubura A. Enterolactone induces apoptosis and inhibits growth of Colo 201 human colon cancer cells both in vitro and in vivo. Anticancer Res 2005;25:2269-76.

[19] Nurmi T, Mursu J, Peñalvo JL, Poulsen HE, Voutilainen S. Dietary intake and urinary excretion of lignans in Finnish men. Br J Nutr 2010;103:677-85.

[20] Bach Knudsen KE, Serena A, Kjaer AK, Tetens I, Heinonen SM, Nurmi T, Adlercreutz H. Rye bread in the diet of pigs enhances the formation of enterolactone and increases its levels in plasma, urine and feces. J Nutr 2003;133:1368-75.

[21] Ringsdorf H, Schlarb B, Venzmer J. Molecular architecture and function of polymeric oriented systems: models for the study of organization, surface recognition, and dynamics of biomembranes. Angew Chem Int Ed Engl 1988;27:113-58.

[22] Muir AD, Westcott ND. Quantification of the lignan secoisolariciresinol diglucoside in baked goods containing flax seed or flax meal. Proc Flax Inst 1996;56:81-5.

[23] Nagata W. Contributions to the chemistry of $\beta$-lactam antibiotics: 1-oxa nuclear analogs of naturally occurring $\beta$-lactam antibiotics. Pure \& Appl Chem 1989;61:325-36.

[24] Borchardt SA, Allain EJ, Michels JJ, Stearns RF, McCoy WF. Reaction of Acylated Homoserine Lactone Bacterial Signaling Molecules with Oxidized Halogen Antimicrobials. App Env Micro 2001;67:3174-9.

[25] Chem Office Ultra 6.0. Biotech Software and Internet Report 2001;2:1-5.

[26] Wang W, VanAlstyne PC, Irons KA, Chen S, Stewart JW, Birt DF. Individual and interactive effect of apigenin analogues on $\mathrm{G} 2 / \mathrm{M}$ cell cycle arrest in human colon carcinoma celllines. Nutr Cancer 2004;48:106-14. 
[27] Ayella AK, Trick HN, Wang W. Enhanced lignan biosynthesis by over-expressing pinoresinol lariciresinol reductase in transgenic wheat. Mol Nutr Food Res 2007;51:151826.

[28] Duthie GG, Gardner PT, Kyle JAM. Plant polyphenols: are they the new magic bullet? Proc Nutr Soc 2003;62:599-603. 


\section{Figure Legends}

Figure 1. Chemical structures of the secoisolariciresinol diglucoside (SDG) verse its mammalian metabolite enterolactone.

Figure 2. Comparison of treatment with SDG verse enterolactone in SW480 cells for growth inhibition. The cells were co-cultured with either SDG or enterolactone at $0-40 \mu \mathrm{M}$ for 24-48 hrs. The cell number was counted by hemacytometer. The results are present as Means \pm SEM from 8-11 independent experiments. Means with different superscripts differ significantly, $\mathrm{P} \leq 0.05$

Figure 3. Comparison of treatment with SDG verse enterolactone for cell cycle arrest. The cells were co-cultured with either SDG or enterolactone at $0-40 \mu \mathrm{M}$ for $24-48 \mathrm{hrs}$. The cell cycle analysis was performed by DNA flow cytometry. Results are present as Means \pm SEM from 5-7 independent experiments for SDG treatment and 3-4 independent experiments for enterolactone treatment. Means with different superscripts differ significantly, $\mathrm{P} \leq 0.05$.

Figure 4. Effects of SDG verse enterolactone on the levels of cyclin A protein. The cells were co-cultured with either SDG or enterolactone at 0-40 $\mu \mathrm{M}$ for $48 \mathrm{hrs}$. The levels of cyclin A protein, as measured by Western blotting, significantly increased in the cells treated with SDG at $20-40 \mu \mathrm{M}$ or enterolactone at $40 \mu \mathrm{M}$ when compared to the vehicle control. Values are Mean \pm SEM from 3 independent experiments. Means with different superscripts are significantly different, $P \leq 0.05$.

Figure 5. Representative HPLC chromatograph of SDG treatment verse enterolactone at $40 \mu \mathrm{M}$ for 48 hrs in the cell culture media. Panel A: HPLC chromatograph of commercial standard SDG, enterodiol, and enterolactone; Panel B: HPLC chromatograph of enterolactonetreated medium; Panel C: HPLC chromatograph of SDG-treated medium. 
Figure 6. Stability of SDG verse enterolactone in the media with or without the cells. Either SDG or enterolactone was co-cultured at $40 \mu \mathrm{M}$ in the media without cells or $0-40 \mu \mathrm{M}$ with SW480 cells for $48 \mathrm{hrs}$. The levels of SDG or enterolactone in the medium extract with or without the cells were determined by HPLC method. Results are present as Means \pm SEM from 3-4 independent experiments, ${ }^{*} \mathrm{P} \leq 0.05$ vs. SDG treatment.

Figure 7. Representative HPLC chromatograph of SDG treatment verse enterolactone in the intracellular extracts. Panel A: HPLC chromatograph of commercial standard SDG, enterodiol, enterolactone, and internal standard flavone; Panel B: intracellular detection of enterolactone in $40 \mu \mathrm{M}$ of enterolactone-treated cells for $48 \mathrm{hrs}$; Panel C: HPLC chromatograph of intracellular extracts in $40 \mu \mathrm{M}$ of SDG-treated cells for $48 \mathrm{hrs}$.

Figure 8. HPLC-MS/ESI chromatograph of SDG (Panel A) and enterolactone (Panel B). 


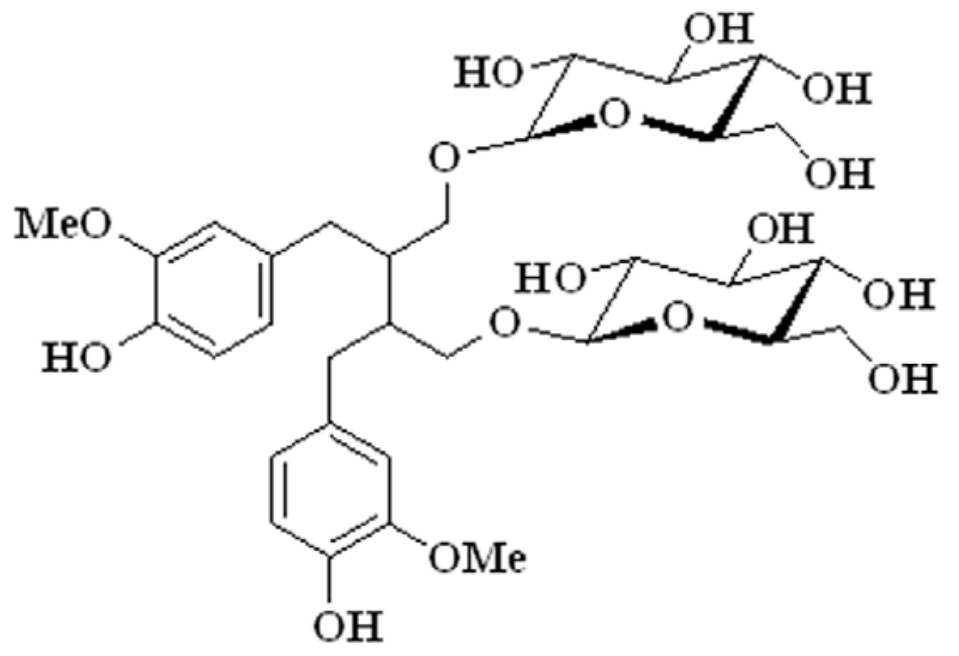

Secoisolariciresinol diglucoside (SDG)<smiles>O=C1OCC(Cc2cccc(O)c2)C1Cc1cccc(O)c1</smiles>

Enterolactone

Fig. 1
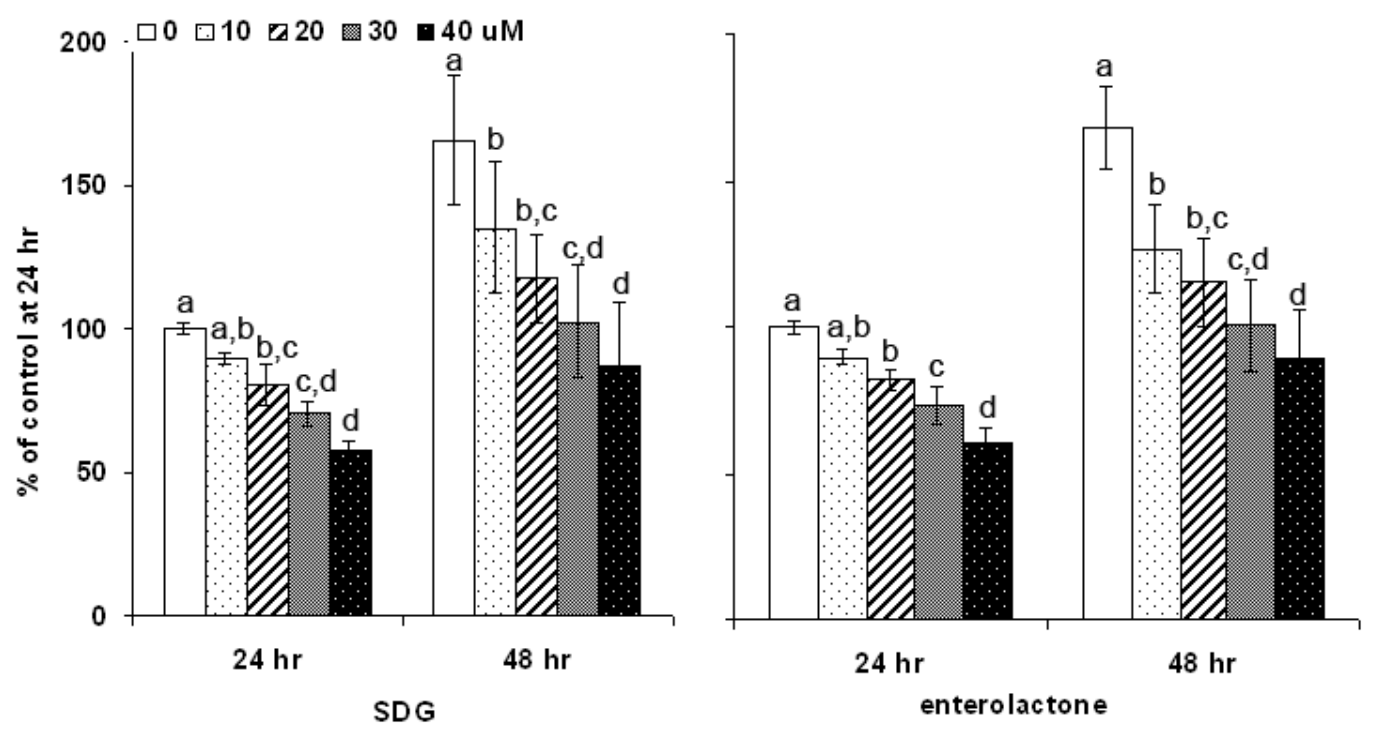

Fig. 2

Page 20 of 23 


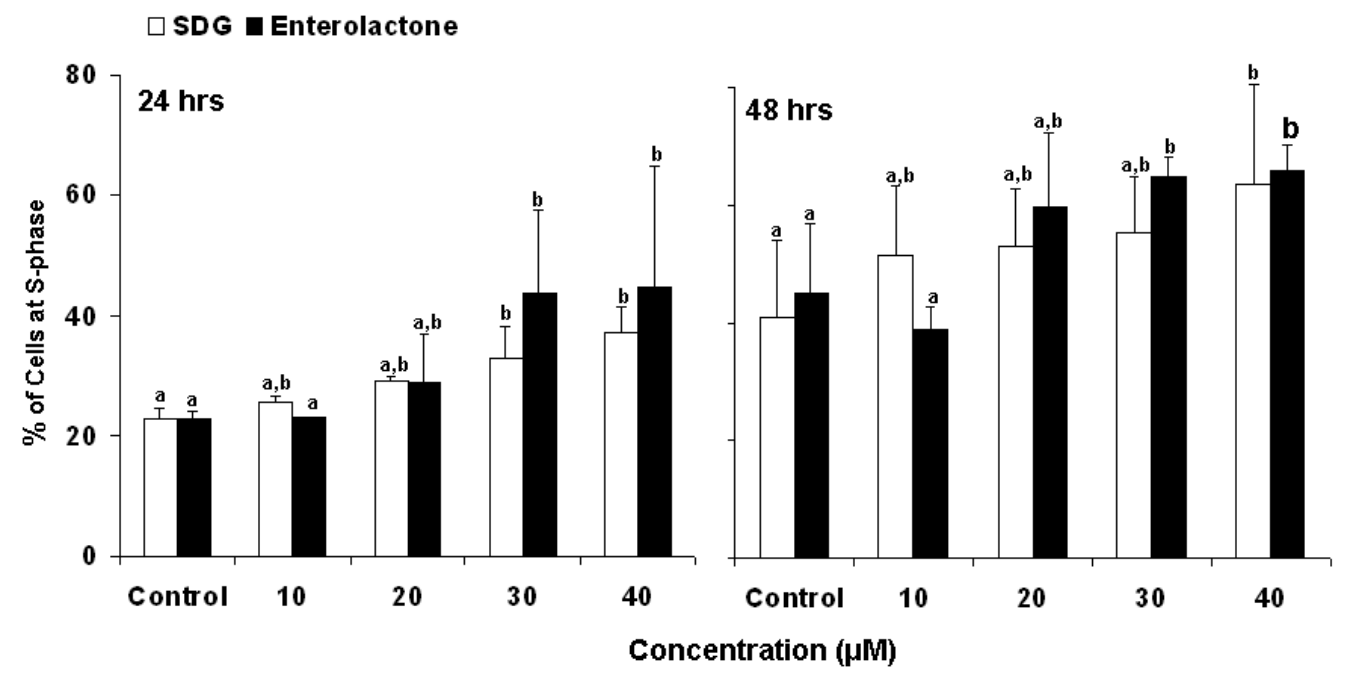

Fig. 3
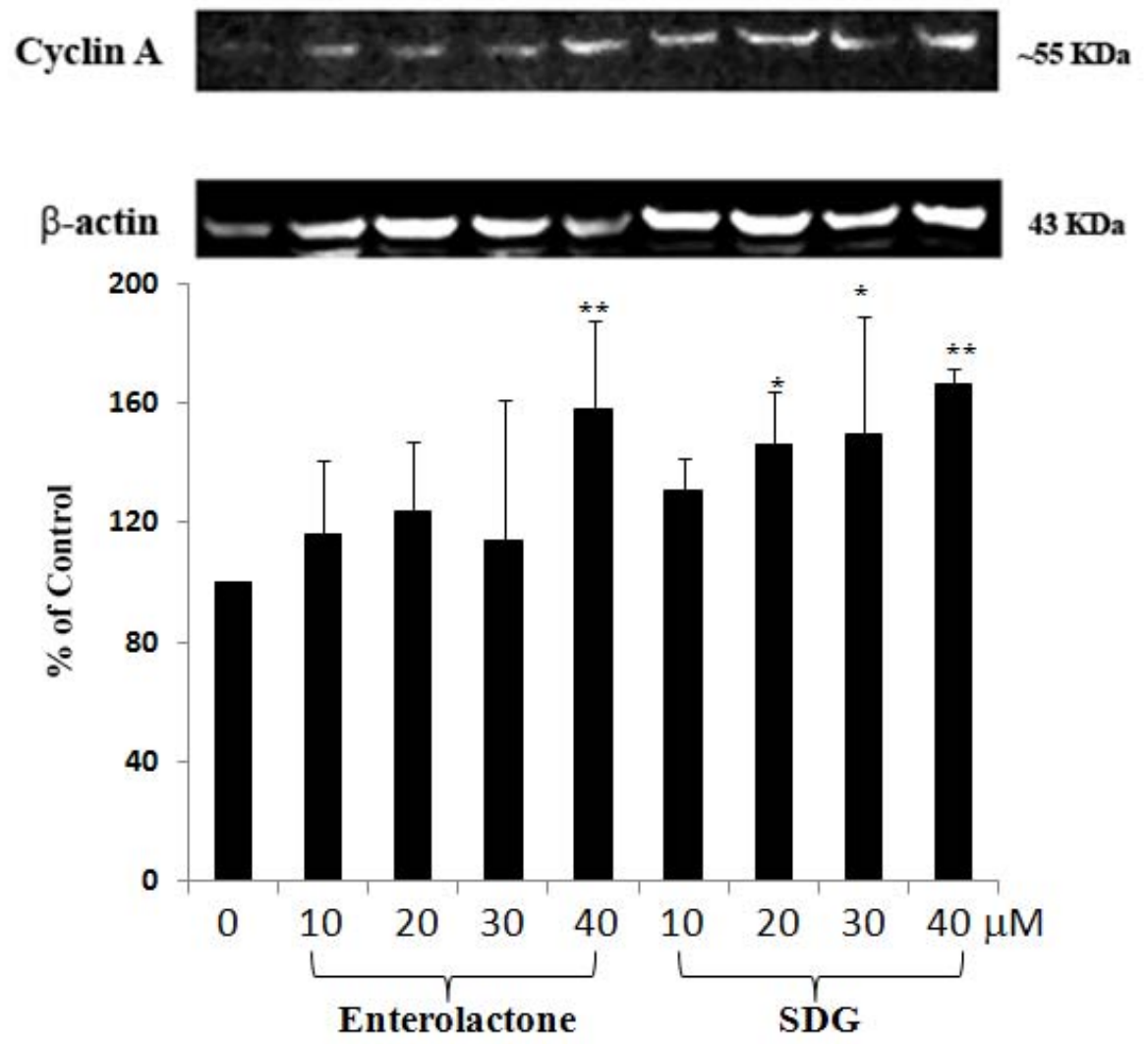

Fig. 4

Page 21 of 23 


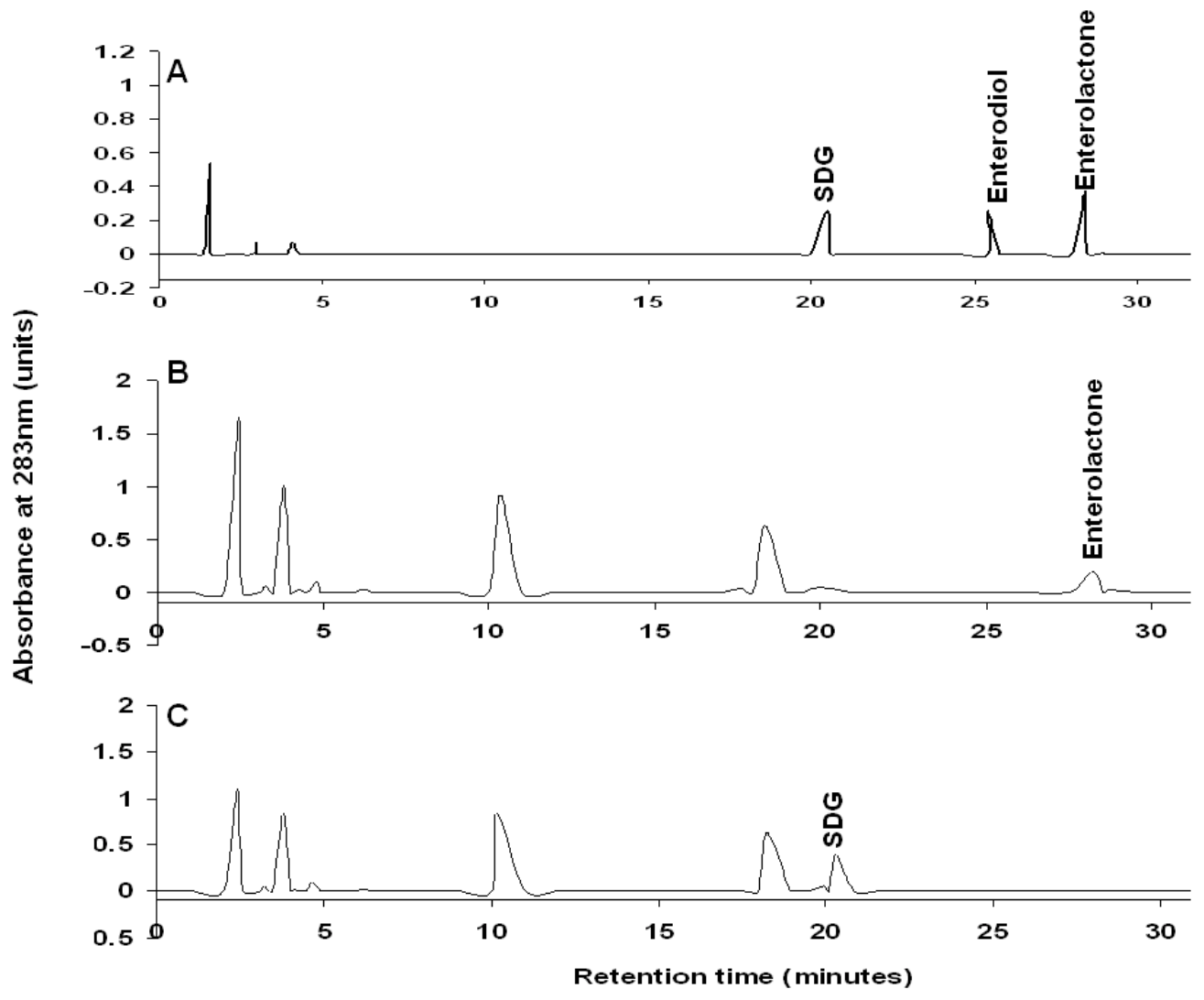

Fig. 5

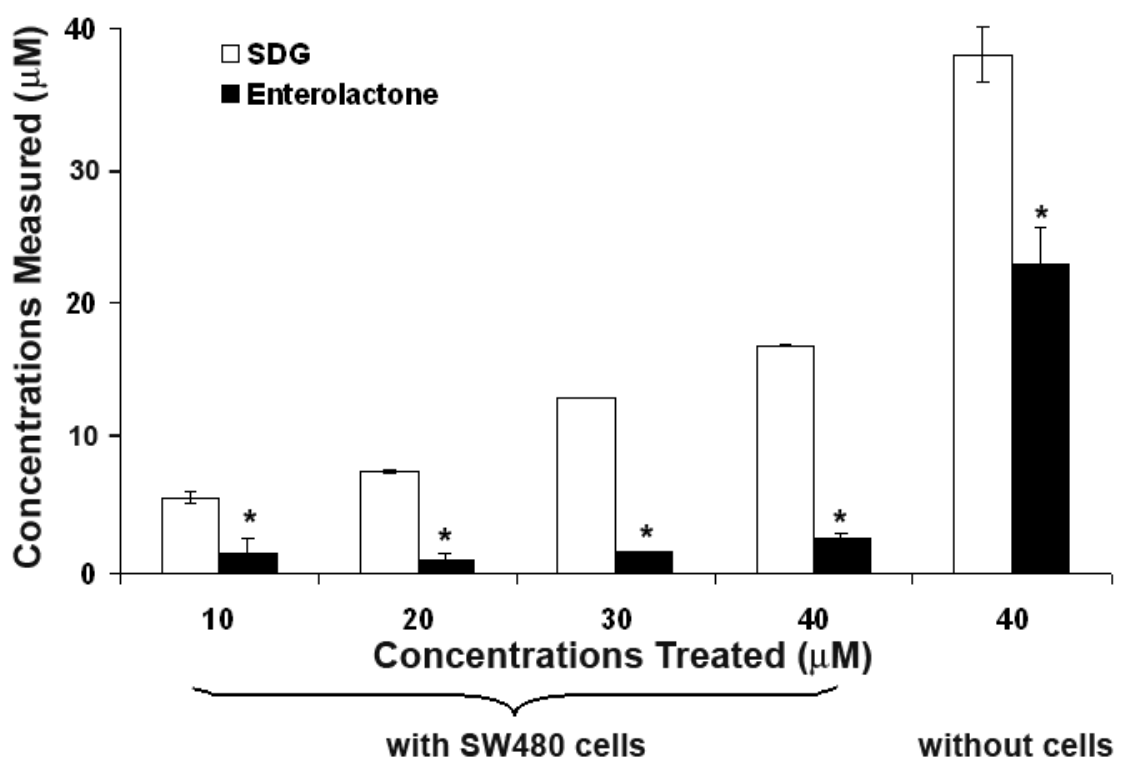

Fig. 6

Page 22 of 23 


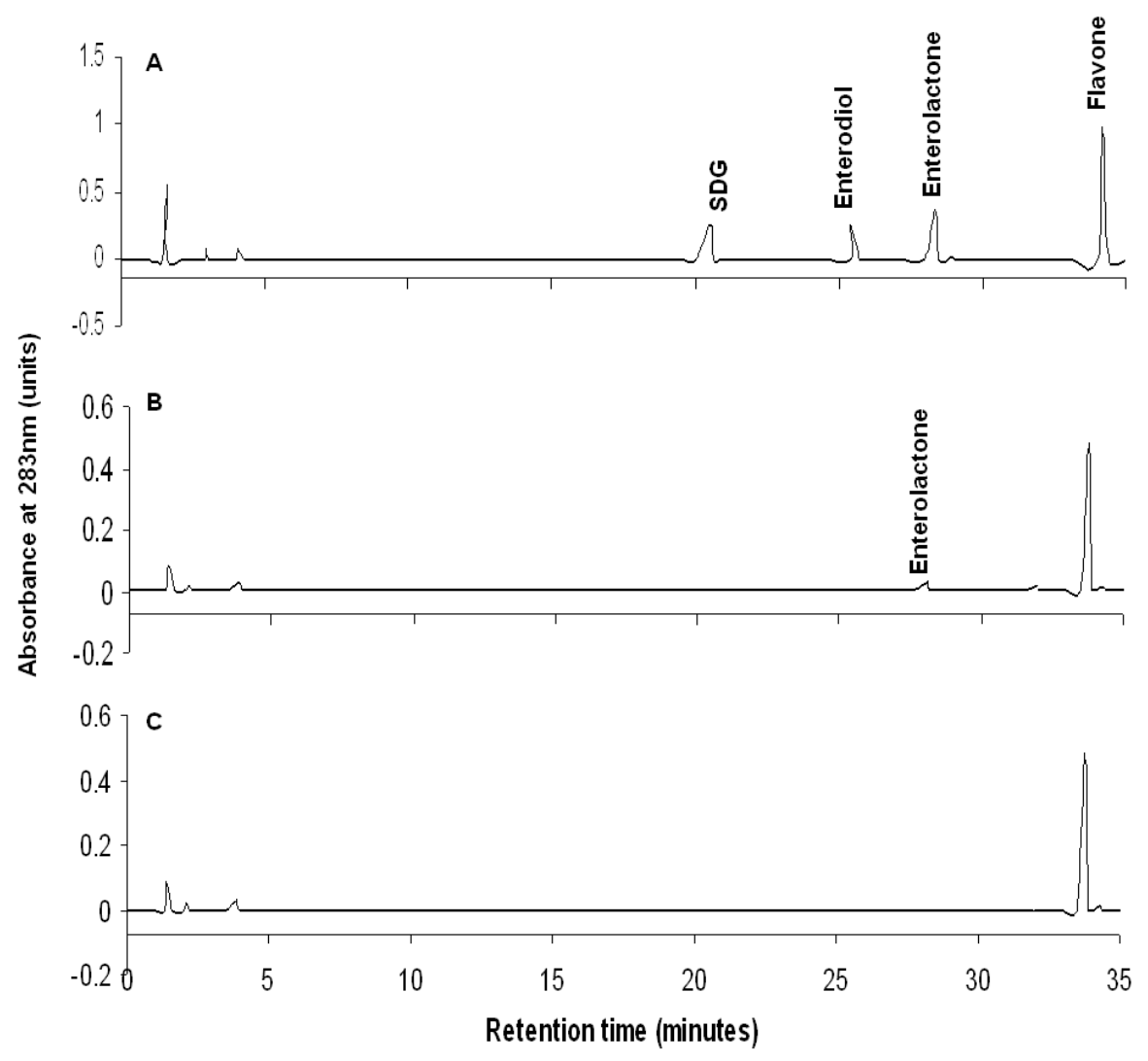

Fig. 7

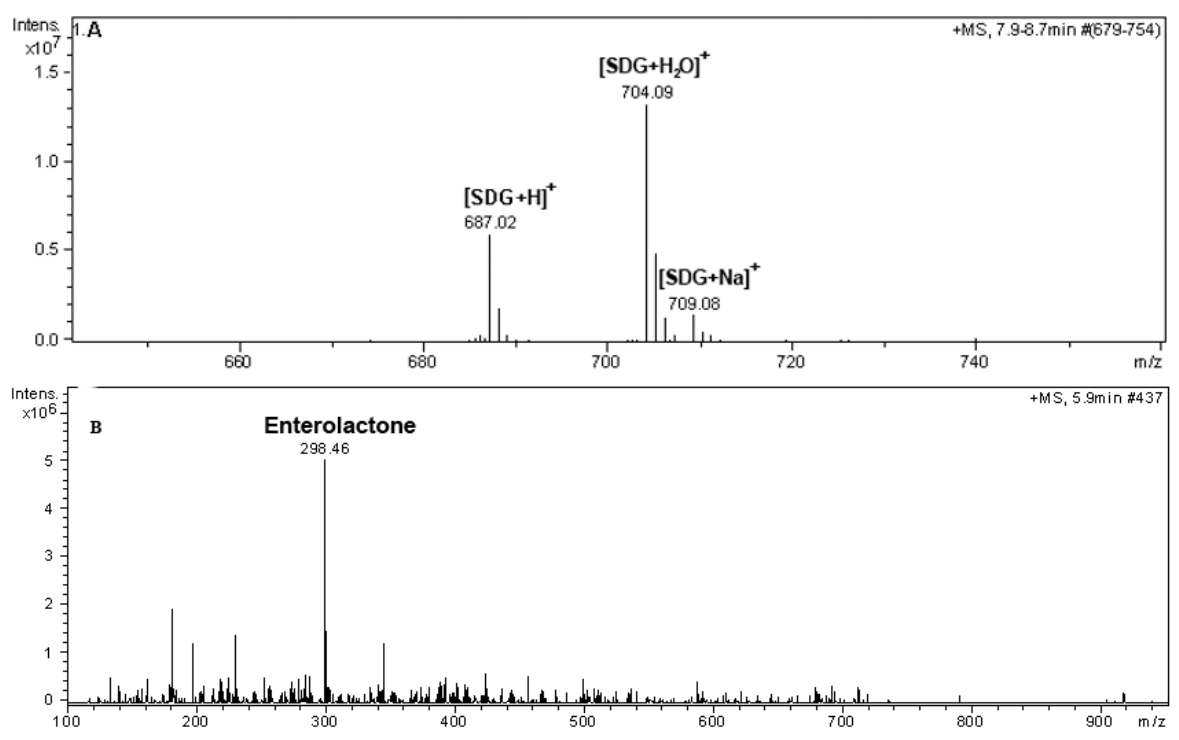

Fig. 8

Page 23 of 23 